of aortic stenosis by Doppler ultrasound. Br Heart J 43:284, 1980.

13. Holen J, Aaslid R, Landmark K, Simonsen S: Determination of pressure gradient in mitral stenosis with a non-invasive ultrasound Doppler technique. Acta Med Scand 199:455, 1976.

14. Gorlin R, Gorlin G: Hydraulic formula for calculation of area of stenotic mitral valve, other cardiac valves, and central circulatory shunts. AM HEART J 41:1, 1951.

15. Smith MD, Dawson PL, Elion JL, Booth DC, Kwan OL, DeMaria AN: Correlation of continuous-wave Doppler velocities with cardiac catheterization gradients: An experimental model of aortic stenosis. J Am Coll Cardiol (December, 1985, volume 6 , in press)

16. Morrow AG, Roberts WC, Ross J Jr, Fisher DR, Behrendt DM, Mason DT, Braunwald E: Clinical staff conference. Obstruction to left ventricular outflow. Current concepts of management and operative treatment. Ann Intern Med 69:1255, 1968.

17. Hatle L, Brubakk A, Tromsdal A, Angelsen B: Noninvasive assessment of pressure drop in mitral stenosis by Doppler ultrasound. Br Heart J 40:131, 1978.
18. Berger M, Berdoff RL, Gallerstein PE, Goldberg E: Evaluation of aortic stenosis by continuous-wave Doppler ultrasound. J Am Coll Cardiol 3:150, 1984.

19. Stamm RB, Martin RP: Quantification of pressure gradients across stenotic valves hy Doppler ultrasound. J Am Coll Cardiol 2:707, 1983.

20. Warth DC, Stewart WJ, Block PC, Weyman AE: A new method to calculate aortic valve area without left heart catheterization. Circulation 70:978, 1984.

21. Kosturakis D, Allen HD, Goldberg SJ, Sahn DJ, Valdes-Cruz LM: Noninvasive quantification of stenotic semilunar valve areas by Doppler echocardiography. J Am Coll Cardiol 3:1256, 1984 .

22. Currie PJ, Seward JB, Reeder GS, Vlietstra RE, Bresnahan DR, Bresnahan JF, Smith HC, Hagler DJ, Tajik AJ: Continuous-wave Doppler echocardiographic assessment of severity of calcific aortic stenosis: A simultaneous Doppler-catheter correlative study in 100 adult patients. Circulation 71:1162, 1985.

\title{
Effect of programmed ventricular stimulation on myocardial lactate extraction in patients with and without coronary artery disease
}

\begin{abstract}
The arterial-coronary sinus lactate difference was measured in 17 patients after each step of a programmed ventricular stimulation protocol consisting of single, double, and triple extrastimuli, first at a basic drive cycle length of $600 \mathrm{msec}$, then at $400 \mathrm{msec}$, with an inter-train interval of 4 seconds. Four patients had no structural heart disease, four had an idiopathic dilated cardiomyopathy, and nine had coronary artery disease with a significant stenosis in at least one branch of the left coronary artery. Net myocardial lactate production during programmed ventricular stimulation was observed in three patietns with coronary artery disease, but not in any patient without coronary artery disease. Among the patients who had coronary artery disease, net myocardial lactate production generally occurred in the patients who had more severe coronary artery disease. Exercise-induced ischemia, as demonstrated by a stress thallium-201 test, did not correlate with myocardial lactate production during programmed ventricular stimulation. Programmed ventricular stimulation, with a stimulation protocol typically used in many electrophysiology laboratories, is capable of inducing myocardial ischemia in at least some patients who have coronary artery disease. This finding suggests that myocardial ischemia may potentially influence the results of programmed ventricular stimulation in some patients with coronary artery disease. (AM HEART J 111:252, 1986)
\end{abstract}

Fred Morady, M.D., Lorenzo A. DiCarlo, Jr., M.D., Ryszard B. Krol, M.D., Michael de Buitleir, M.B., John M. Nicklas, M.D., and Thomas M. Annesley, Ph.D. Ann Arbor, Mich.

From the Division of Cardiology, Department of Internal Medicine, and Department of Pathology, University of Michigan Medical Center, University Hospitals.

Received for publication Aug. 2, 1985; accepted Aug. 26. 1985.

Reprint requests: Fred Morady, M.D., Division of Cardiology, Room W-11511. University Hospitals, 1405 East Ann St., Ann Arbor, MI 48109.
Myocardial ischemia occurring during programmed ventricular stimulation could potentially affect the induction of ventricular tachycardia. However, the effects of programmed ventricular stimulation on myocardial metabolism have not been well defined. Only one preliminary report described the effects of 
Table I. Clinical features of patients studied

\begin{tabular}{|c|c|c|c|c|c|c|c|}
\hline \multirow{2}{*}{$\begin{array}{c}\text { Patient } \\
\text { no. }\end{array}$} & \multirow[b]{2}{*}{ Age/Sex } & \multirow{2}{*}{$\begin{array}{l}\text { Heart } \\
\text { disease }\end{array}$} & \multirow[b]{2}{*}{$L V E F$} & \multicolumn{3}{|c|}{$\begin{array}{l}\text { Coronary artery stenosis } \\
\text { (percent of diameter) }\end{array}$} & \multirow{2}{*}{$\begin{array}{l}\text { Ischemia during } \\
\text { stress thallium tes }\end{array}$} \\
\hline & & & & $L A D$ & $L C$ & $R C A$ & \\
\hline 1 & $58 / \mathrm{M}$ & None & 0.58 & 0 & 0 & 0 & \\
\hline 2 & $28 / \mathrm{F}$ & None & 0.62 & 0 & 0 & 0 & - \\
\hline 3 & $43 / F$ & None & 0.60 & 0 & 0 & 0 & - \\
\hline 4 & $41 / \mathrm{M}$ & None & 0.58 & 0 & 0 & 0 & - \\
\hline 5 & $52 / \mathrm{M}$ & IDC & 0.25 & 0 & 0 & 0 & - \\
\hline 6 & $62 / \mathrm{M}$ & IDC & 0.18 & 0 & 0 & 0 & - \\
\hline 7 & $49 / \mathrm{M}$ & IDC & 0.22 & 0 & 0 & 0 & - \\
\hline 8 & $57 / \mathrm{M}$ & IDC & 0.28 & 0 & 0 & 0 & - \\
\hline 9 & $74 / \mathrm{M}$ & $\mathrm{CAD}$ & 0.16 & 100 & 100 & 50 & - \\
\hline 10 & $57 / \mathrm{F}$ & CAD & 0.30 & 95 & 100 & 95 & - \\
\hline 11 & $70 / \mathrm{M}$ & $\mathrm{CAD}$ & 0.27 & 80 & $<50$ & 100 & + \\
\hline 12 & $62 / \mathrm{M}$ & $\mathrm{CAD}$ & 0.24 & 80 & $<50$ & 100 & + \\
\hline 13 & $72 / \mathrm{M}$ & $\mathrm{CAD}$ & 0.60 & 60 & 80 & 100 & + \\
\hline 14 & $61 / \mathrm{M}$ & $\mathrm{CAD}$ & 0.32 & $90^{*}$ & $95^{\dagger}$ & $90^{*}$ & + \\
\hline 15 & $65 / \mathrm{F}$ & CAD & 0.32 & $90^{*}$ & $80^{*}$ & $100^{*}$ & 0 \\
\hline 16 & $35 / \mathrm{M}$ & CAD & 0.40 & 100 & 0 & 0 & 0 \\
\hline 17 & $58 / \mathbf{F}$ & CAD & 0.15 & 80 & 80 & 100 & + \\
\hline
\end{tabular}

Abbreviations and symbols: $\mathrm{CAD}=$ coronary artery disease; IDC = idiopathic dilated cardiomyopathy; $\mathrm{LAD}=$ left anterior descending coronary artery; $\mathrm{LC}=$ left circumflex coronary artery; $\mathrm{LVEF}=$ left ventricular ejection fraction; $\mathrm{RCA}=$ right coronary artery; $+=$ present; $0=$ absent; $-=$ not determined.

*Patent saphenous vein graft distal to stenosis.

tOccluded saphenous vein graft distal to stenosis.

programmed ventricular stimulation on the arterialcoronary sinus lactate difference. Negative lactate extraction, i.e., lactate production, was demonstrated in each of eight consecutive patients with coro-nary artery disease who underwent programmed stimulation with a protocol consisting of single and double extrastimuli, a basic drive cycle length as short as $330 \mathrm{msec}$, and a 3-second intertrain interval. ${ }^{1}$ In many electrophysiology laboratories the stimulation protocol includes triple extrastimuli, a shortest basic drive cycle length of $400 \mathrm{msec}$ and a 4-second inter-train interval. ${ }^{2-7}$ The effects of this type of stimulation protocol on myocardial metabolism have not been described.

Because the functional consequences of coronary artery stenoses are extremely variable, the effects of programmed ventricular stimulation on myocardial lactate production would not be expected to be similar in all patients with coronary artery disease. However, the factors associated with myocardial ischemia during programmed ventricular stimulation in patients with coronary artery disease have not been characterized. Also unclear is whether programmed ventricular stimulation may precipitate myocardial ischemia in patients without coronary artery disease, e.g., patients with dilated cardiomyopathy.

The present study was designed to answer the following three questions: (1) How often is myocardial ischemia precipitated by a programmed ventricular stimulation protocol which includes single, double, and triple extrastimuli, basic drive cycle lengths of 600 and $400 \mathrm{msec}$, and a 4-second inter-train interval? (2) In patients who have coronary artery disease, what factors are associated with the development of myocardial ischemia during programmed ventricular stimulation? (3) Is myocardial ischemia precipitated by programmed ventricular stimulation in patients without heart disease or with dilated cardiomyopathy and severely impaired left ventricular function?

\section{METHODS}

Patient characteristics. Seventeen patients who underwent a clinically indicated electrophysiologic study provided informed consent to participate in this study under a protocol approved by the Committee on Human Research at the University of Michigan. Only patients who had undergone a cardiac catheterization including coronary angiography, within 2 months of the electrophysiologic study were asked to participate.

The patient's clinical features are described in Table I. There were 12 men and 5 women, with a mean age of $55 \pm 13$ years ( \pm standard deviation). Four patients had no identifiable structural heart disease. Four patients had an idiopathic dilated cardiomyopathy and a mean left ventricular ejection fraction of $0.23 \pm 0.04$. Nine patients 
Table II. Net myocardial lactate extraction during programmed ventricular stimulation

\begin{tabular}{|c|c|c|c|c|c|c|c|}
\hline \multirow[b]{3}{*}{ Patient no. } & \multicolumn{7}{|c|}{ Percent lactate extraction } \\
\hline & \multirow[b]{2}{*}{ Baseline } & \multicolumn{3}{|c|}{$B D C L 600 \mathrm{msec}$} & \multicolumn{3}{|c|}{$B D C L 400 \mathrm{msec}$} \\
\hline & & $S_{2}$ & $S_{2} S_{3}$ & $S_{2} S_{3} S_{4}$ & $S_{2}$ & $S_{2} S_{3}$ & $S_{2} S_{3} S_{4}$ \\
\hline \multicolumn{8}{|c|}{ Patients without structural heart disease } \\
\hline 1 & 37 & 56 & 50 & 35 & 46 & 42 & 26 \\
\hline 2 & 20 & 24 & 18 & 14 & 22 & 12 & 13 \\
\hline 3 & 39 & 33 & 34 & 37 & 29 & 32 & 28 \\
\hline 4 & 50 & 47 & 60 & 52 & 53 & 59 & 60 \\
\hline \multicolumn{8}{|c|}{ Patients with idiopathic dilated cardiomyopathy } \\
\hline 5 & 38 & 38 & 41 & 30 & 45 & 36 & 35 \\
\hline 6 & 26 & 25 & 29 & 31 & 32 & 30 & 34 \\
\hline 7 & 73 & 67 & 60 & 60 & 61 & 60 & 64 \\
\hline 8 & 46 & 30 & 37 & 40 & 39 & 35 & 40 \\
\hline \multicolumn{8}{|c|}{ Patients with coronary artery disease } \\
\hline 9 & 32 & 40 & 30 & 23 & 14 & 43 & -5 \\
\hline 10 & 33 & 12 & -16 & -11 & -36 & -42 & $\mathrm{ND}^{*}$ \\
\hline 11 & 17 & -47 & -40 & -6 & 14 & 1 & -22 \\
\hline 12 & 19 & 19 & 17 & 6 & 4 & 27 & 6 \\
\hline 13 & 30 & 24 & 33 & 22 & 28 & 32 & $\mathrm{ND}^{*}$ \\
\hline 14 & 32 & 24 & 26 & 35 & 34 & 37 & 27 \\
\hline 15 & 32 & 33 & 22 & 14 & 19 & 21 & 16 \\
\hline 16 & 63 & 57 & 64 & 67 & 67 & 71 & 68 \\
\hline 17 & 36 & 29 & 30 & 33 & 19 & 26 & 32 \\
\hline
\end{tabular}

Abbreviations: $\mathrm{BDCL}=$ basic drive cycle length; $\mathrm{S}_{2}=$ first extrastimulus; $\mathrm{S}_{2}=$ second extrastimulus; $\mathrm{S}_{4}=$ third extrastimulus.

* Not determined because ventricular tachycardia was induced.

had a significant coronary artery stenosis $(\geq 70 \%$ of diameter) in at least either the left anterior descending or left circumflex coronary artery. In two patients who had undergone coronary artery bypass grafting, one had patent grafts to all vessels (patient No. 15), whereas the other (patient No. 14) had an occluded graft to a large branch of the left circumflex coronary artery. In the patients with coronary artery disease, the mean left ventricular ejection fraction was $0.31 \pm 0.14$ (range 0.15 to $0.60)$.

A thallium-201 exercise test (Bruce protocol) was performed in seven of the nine patients who had coronary artery disease. A treadmill test was not performed in two patients (Nos. 9 and 10) who were debilitated.

Electrophysiologic study. The electrophysiologic study was performed in the fasting, unsedated state. Antiarrhythmic drugs were discontinued 4 or more half-lives before the study, and all forms of nitrate therapy were discontinued for at least 4 hours before the study. Between one and three electrode catheters were inserted percutaneously through a femoral vein; one was positioned against the right ventricular apex and the others were positioned depending on the clinical indication for the electrophysiologic study. A No. 6 or 7 French central lumen catheter was inserted through a brachial or subclavian vein and was positioned within the proximal portion of the coronary sinus. A No. 5 French cannula was inserted percutaneously into a femoral artery for continuous monitoring of the arterial blood pressure.

ECG leads $V_{1}, I$, and III, the right ventricular apex electrogram, and the mean atrial blood pressure were recorded at a paper speed of 25 to $50 \mathrm{~mm} / \mathrm{sec}$ on an Electronics for Medicine VR-12 recorder. Programmed stimulation was performed with stimuli which had a duration of $2 \mathrm{msec}$ and a current intensity of 0.8 to $1 \mathrm{~mA}$ (two to three times the diastolic excitability threshold).

Programmed ventricular stimulation protocol. Using basic drive trains of eight stimuli $\left(S_{1}\right)$ at a cycle length of $600 \mathrm{msec}$ and a 4-second inter-train interval, a single extrastimulus $\left(\mathrm{S}_{2}\right)$ was introduced 450 msec after the last $S_{1}$, and the $S_{1}-S_{2}$ interval was decreased by 10 msec steps to the point of ventricular refractoriness. $S_{2}$ was positioned $30 \mathrm{msec}$ beyond the point of refractoriness and a second extrastimulus $\left(\mathrm{S}_{3}\right)$ was then introduced $300 \mathrm{msec}$ beyond $S_{2}$. The $S_{2}-S_{3}$ interval was decreased by $10 \mathrm{msec}$ steps till $S_{3}$ no longer evoked a response. The $S_{1}-S_{2}$ interval was shortened by $10 \mathrm{msec}$ steps till $S_{3}$ again evoked a response, then the $S_{2}-S_{3}$ interval was shortened till $S_{3}$ no longer evoked a response. This process was continued till $S_{2}$ reached ventricular refractoriness. $S_{2}$ and $S_{3}$ were then positioned $30 \mathrm{msec}$ beyond their points of refractoriness and a third extrastimulus $\left(S_{4}\right)$ was introduced $300 \mathrm{msec}$ beyond $S_{3}$. The $S_{3}-S_{4}$ interval was shortened by $10 \mathrm{msec}$ steps till $S_{1}$ no longer evoked a response. The $S_{1}-S_{2}, S_{2}-S_{3}$, and $S_{3}-S_{4}$ intervals were then sequentially shortened by 10 msec till $S_{2}$ reached ventricular refractoriness. This stimulation sequence was then repeated at a basic drive cycle length of $400 \mathrm{msec}$, starting with an $\mathrm{S}_{1}-\mathrm{S}_{2}$ interval of 350 msec.

Serum lactate determinations. Blood samples of $3 \mathrm{cc}$ were drawn simultaneously from the femoral artery and coronary sinus. Lactate levels were determined enzymati- 
cally on a centrifugal analyzer. Baseline samples were drawn before starting the stimulation protocol and subsequent samples were drawn immediately upon completion of each step of the stimulation protocol. While samples were being drawn, stimulation with the basic drive trains was continued. Final samples were drawn from the femoral artery and coronary sinus 5 minutes after completion of the stimulation protocol.

Ventricular tachycardia was induced by the stimulation protocol described above in four patients. In two patients (Nos. 10 and 13) sustained ventricular tachycardia requiring direct-current countershock was induced by triple extrastimuli at a basic drive cycle length of $400 \mathrm{msec}$, and no blood samples for lactate determinations were available for this step of the protocol. In another two patients (Nos. 14 and 15), ventricular tachycardia not requiring direct-current countershock was induced by triple extrastimuli at a basic drive cycle length of $400 \mathrm{msec}$. In these two patients the stimulation protocol was repeated and samples were drawn during stimulation at a basic drive cycle length of $400 \mathrm{msec}$ with triple extrastimuli when the coupling intervals of the extrastimuli were within 10 to 20 msec of the coupling intervals which had induced ventricular tachycardia previously.

No patient experienced angina pectoris during the stimulation protocol, and no patient was given any form of nitrate therapy.

The arterial-coronary sinus lactate difference divided by the arterial lactate level $\times 100$ was expressed as "percent lactate extraction."

Statistical analysis. Comparisons of the mean arterial blood pressure during programmed stimulation between patients in whom net myocardial lactate production was and was not observed were performed with a Student's $t$ test, with $p<0.05$ accepted as significant.

\section{RESULTS}

Patients without identifiable structural heart disease. In each of the four patients without identifiable heart disease, there was myocardial lactate extraction and no net lactate production throughout the ventricular stimulation protocol (Table II).

Patients with idiopathic dilated cardiomyopathy. There was no net myocardial lactate production during programmed ventricular stimulation in the four patients who had an idiopathic dilated cardiomyopathy (Table II).

Patients with coronary artery disease. There was net myocardial lactate production, i.e., negative lactate extraction, in three patients who had coronary artery disease (Nos. 9 to 11, Table II). The earliest step in the stimulation protocol at which net myocardial lactate extraction became negative was three extrastimuli at a basic drive cycle length of $400 \mathrm{msec}$ in patient No. 9, two extrastimuli at a basic drive cycle length of $600 \mathrm{msec}$ in patient No. 10, and one extrastimulus at a basic drive cycle length of 600 msec in patient No. 11. In each of these three patients, net myocardial lactate extraction returned to baseline values 5 minutes after completion of the stimulation protocol.

In the remaining six patients who had coronary artery disease, there was no net myocardial lactate production.

There was no significant difference in the mean arterial blood pressure during sinus rhythm between the three patients in whom there was net myocardial lactate production $(83 \pm 6 \mathrm{~mm} \mathrm{Hg}$ ) and the six in whom there was not $(83 \pm 13 \mathrm{~mm} \mathrm{Hg}, p>0.05)$. There was no significant difference in the minimum mean arterial blood pressure during programmed stimulation with triple extrastimuli between patients in whom net myocardial lactate production did and did not occur, either when the basic drive cycle length was $600 \mathrm{msec}(63 \pm 15 \mathrm{~mm} \mathrm{Hg}$ vs $78 \pm 16 \mathrm{~mm} \mathrm{Hg}, p>0.05)$, or $400 \mathrm{msec}(54 \pm 14 \mathrm{~mm}$ $\mathrm{Hg}$ vs $66 \pm 14 \mathrm{~mm} \mathrm{Hg}, p>0.05$ ).

The mean left ventricular ejection fraction among the three patients in whom there was net myocardial lactate production was $0.24 \pm 0.07$, compared to $0.33 \pm 0.15$ among the six patients in whom there was not $(p>0.05)$.

The patients in whom there was net myocardial lactate production each had double- or triple-vessel disease, and two of the three patients had a significant stenosis in both the left anterior descending and the left circumflex coronary arteries. The coronary artery disease was generally less severe in the patients who did not demonstrate net myocardial lactate production during programmed ventricular stimulation. Only one of the six patients had a significant stenosis in both the left anterior descending and the left circumflex coronary artery.

Exercise-induced ischemia did not correlate well with net myocardial lactate production during programmed ventricular stimulation. One of the three patients in whom there was net myocardial lactate production during programmed ventricular stimulation had evidence of myocardial ischemia in stage II of a stress thallium-201 test. An exercise test was not performed in the other two patients because of general debility. Among the six patients without net transmyocardial lactate production during programmed ventricular stimulation, four had evidence of myocardial ischemia demonstrated in stage I or II of a stress thallium-201 test.

\section{DISCUSSION}

The results of this study demonstrate that programmed ventricular stimulation with a stimulation protocol typically used in many electrophysiology laboratories is capable by itself of provoking myocardial ischemia in at least some patients who have 
coronary artery disease. In contrast, myocardial ischemia is not provoked by programmed ventricular stimulation in patients without coronary artery disease, regardless of whether left ventricular function is normal or severely impaired.

There was a wide range of $17 \%$ to $73 \%$ in the baseline levels of myocardial lactate extraction in the heterogeneous group of patients in this study. However, a wide range ( $5 \%$ to $55 \%)$ in resting myocardial lactate extraction has been observed even in a homogeneous group of normal subjects. ${ }^{8}$ Because of this wide range in myocardial lactate extraction in normal subjects, any absolute value of myocardial lactate extraction short of production cannot be considered abnormal. ${ }^{8}$ In the present study, although several patients demonstrated a fall in net myocardial lactate extraction at some point in the stimulation protocol, net myocardial lactate production occurred during programmed ventricular stimulation in only three of the nine patients with coronary artery disease.

Determinants of lactate production during programmed stimulation. Regarding the determinants of net myocardial lactate production during programmed ventricular stimulation in patients with coronary artery disease, although the fall in mean arterial blood pressure during programmed stimulation tended to be of greater magnitude in patients in whom there was net myocardial lactate production compared to patients in whom net myocardial lactate production did not occur, the difference did not attain statistical significance. There was also no significant difference in the mean left ventricular ejection fraction between the two groups of patients.

The patients who had evidence of myocardial ischemia during programmed stimulation in general had more severe coronary artery disease. It might be expected that net myocardial lactate production during programmed ventricular stimulation would correlate with the presence of exercise-induced ischemia. Accordingly, one of the three patients in whom myocardial ischemia was provoked by programmed stimulation also had evidence of exerciseinduced ischemia. Because the two patients who were not able to exercise had a recent history of angina pectoris provoked by mild or moderate exertion, it is likely that ischemia would also have been demonstrated by exercise testing in these two patients. However, four of the patients who did not have evidence of ischemia during programmed stimulation had documented exercise-induced ischemia; it can therefore be concluded that a positive exercise test does not necessarily predict the occurrence of myocardial ischemia during programmed ventricular stimulation.

It is noteworthy that none of the three patients in whom net myocardial lactate production occurred during programmed ventricular stimulation experienced angina pectoris during the electrophysiologic study. Because each of these patients had a recent history of exertional angina pectoris, the absence of angina pectoris during ischemia provoked by programmed stimulation cannot be attributed to a defective pain mechanism. This may suggest that the degree of ischemia induced by programmed stimulation was mild relative to the ischemia induced in these patients by exercise.

Comparison with results of a prior study. Borggrefe et al. ${ }^{1}$ reported in preliminary form that there was net myocardial lactate production in eight consecutive patients with coronary artery disease who underwent programmed stimulation, with a protocol which included single and double extrastimuli, basic drive cycle lengths between 500 and $330 \mathrm{msec}$, and an inter-train interval of 3 seconds. ${ }^{1}$ In contrast, the protocol used in the present study included up to three extrastimuli, basic drive cycle lengths of 600 and $400 \mathrm{msec}$, and a 4-second inter-train interval. In both studies, myocardial ischemia was provoked in some patients by programmed stimulation with only one or two extrastimuli at relatively long basic drive cycle lengths of $500 \mathrm{msec}$ or more. However, because the severity of the coronary artery disease was not specified in the preliminary report of Borggrefe et al., ${ }^{1}$ and because the inter-train interval was different, the results of the two studies are not comparable. The independent effect of the inter-train interval on myocardial lactate production during programmed ventricular stimulation remains to be determined.

With regard to the effect of the basic drive cycle length on myocardial metabolism, it is noteworthy that in patient No. 11 net myocardial lactate production occurred during stimulation with one and two extrastimuli at a basic drive cycle length of 600 msec, but not at $400 \mathrm{msec}$, although the mean arterial pressure fell to a greater degree when the basic drive cycle length was $400 \mathrm{msec}$. Because not all of the determinants of myocardial oxygen supply and demand were assessed in this study, the explanation for the findings in patient No. 11 remains unclear.

Relationship between ischemia and ventricular tachycardia induction. This study was not designed to evaluate the effects of myocardial ischemia on the induction of ventricular tachycardia. However, the demonstration that programmed stimulation by 
itself may provoke myocardial ischemia suggests that myocardial ischemia could potentially influence the results of programmed ventricular stimulation in some patients who have coronary artery disease. Consistent with this possibility are the results of a study by Garan et al. ${ }^{9}$ Ten of 15 patients in whom ventricular tachycardia was inducible by programmed stimulation no longer had inducible ventricular tachycardia after undergoing coronary artery bypass grafting. Therefore, in some patients who have coronary artery disease, myocardial ischemia provoked by programmed ventricular stimulation may play an important role in the induction of ventricular tachycardia.

It is possible that myocardial ischemia may have been provoked in a greater number of patients in this study had the stimulation protocol included bursts of rapid overdrive pacing. The effects of burst pacing on myocardial metabolism were not evaluated, because a standard protocol for burst pacing does not exist. ${ }^{10}$ The cycle lengths at which burst pacing is performed, the duration of burst pacing, and the interval between pacing bursts are extremely variable between different laboratories. ${ }^{10}$

Limitations. A limitation of this study is the inability to detect myocardial ischemia in the distribution of the right coronary artery. Because the right coronary artery does not usually drain into the coronary sinus, only patients who had a significant stenosis in a branch of the left coronary artery were included in this study. However, because several patients also had a significant stenosis in the right coronary artery, it is possible that the effect of programmed ventricular stimulation on myocardial metabolism was underestimated. A second limitation is that measurement of the arterial-coronary sinus lactate difference may not have been a sensitive indicator of localized myocardial ischemia in the distribution of the left coronary artery. Prior studies have demonstrated that there may be release of lactate from the myocardium of patients with coronary artery disease at a time when the arterialcoronary sinus difference shows net myocardial lactate extraction. ${ }^{11,12}$ This may also have resulted in an underestimate of the effects of programmed ventricular stimulation on myocardial metabolism.

Conclusions. In conclusion, programmed ventricular stimulation may induce myocardial ischemia in some patients who have coronary artery disease, but does not do so in patients with a dilated cardiomyopathy or without structural heart disease. This observation suggests that in at least some patients with coronary artery disease, the induction of ventricular tachycardia by programmed ventricular stimulation may not be solely an electrophysiologic phenomenon, but may be influenced by myocardial ischemia. The effect of myocardial ischemia on the induction of ventricular tachycardia during programmed stimulation remains to be determined.

The authors express their gratitude to Lisa Hackbarth for her excellent secretarial assistance.

\section{REFERENCES}

1. Borggrefe M, Kuhn H, Breithardt G: Does programmed ventricular stimulation induce hypoxia of the myocardium? (abstr). Circulation 68:III-243, 1983.

2. Doherty JU, Kienzle MG, Waxman HL, Buxton AE, Marchlinski FE, Josephson ME: Relation of mode of induction and cycle lengths of ventricular tachycardia: Analysis of 104 patients. Am J Cardiol 52:60, 1983.

3. Benditt DG, Benson DW, Jr, Klein GJ, Pritzker MR, Kriett JM, Anderson RW: Prevention of recurrent sudden cardiac arrest: Role of provocative electropharmacologic testing. J Am Coll Cardiol 2:418, 1983.

4. Saksena S, Rothbart ST, Shah Y, Cappello G: Clinical efficacy and electropharmacology of continuous intravenous amiodarone infusion and chronic oral amiodarone in refractory ventricular tachycardia. Am J Cardiol 54:347, 1984.

5. Ezri MD, Huang SK, Denes P: The role of Holter monitoring in patients with recurrent sustained ventricular tachycardia: An electrophysiologic correlation. AM HEART J 108:1229, 1984.

6. McPherson CA, Rosenfeld LE, Batsford WP: Day-to-day reproducibility of responses to right ventricular programmed electrical stimulation: Implications for serial drug testing. Am J Cardiol 55:689, 1985.

7. Morady F, DiCarlo LA, Jr, Liem LB, Krol RB, Baerman JM: Effects of high stimulation current on the induction of ventricular tachycardia. Am J Cardiol 56:73, 1985.

8. Gertz EW, Wisneski JA, Neese R, Houser A, Korte R, Bristow JD: Myocardial lactate extraction: Multi-determined metabolic function. Circulation 61:256, 1980.

9. Garan H, Ruskin JN, DiMarco JP, Derkac WM, Akins CW, Daggett WM, Austen WG, Buckley MJ: Electrophysiologic studies before and after inyocardial revascularization in patients with life-threatening ventricular arrhythmias. Am J Cardiol 51:519, 1983.

10. Akhtar M: Clinical application of rapid ventricular burst pacing versus extrastimulation for induction of ventricular tachycardia. J Am Coll Cardiol 4:305, 1984.

11. Gertz EW, Wisneski JA, Neese R, Bristow JD, Searle GL, Hanlon JT: Myocardia lactate metabolism: Evidence of lactate release during net chemical extraction in man. Circulation 63:1273, 1981.

12. Wisneski JA, Gertz EW, Neese RA, Gruenke LD, Craig JC: Dual carbon-labeled isotope experiments using D- $6-{ }^{14} \mathrm{C}$ glucose and $\mathrm{L}-1,2,3{ }^{13} \mathrm{C}_{3}$ lactate: A new approach for investigating human myocardial metabolism during ischemia. J Am Coll Cardiol 5:1138, 1985. 